Check for updates

Cite this: RSC Adv., 2017, 7, 54947

Received 27th October 2017

Accepted 25th November 2017

DOI: 10.1039/c7ra11844a

rsc.li/rsc-advances

\section{The remineralization effectiveness of PAMAM dendrimer with different terminal groups on demineralized dentin in vitro}

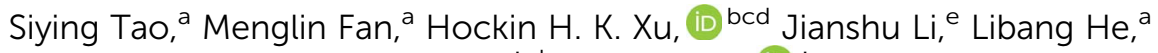 \\ Xuedong Zhou, ${ }^{a}$ Kunneng Liang ${ }^{\star a b}$ and Jiyao Li (D) *a
}

\begin{abstract}
The aim of this study was to examine the dentin remineralization extent that poly(amido amine) (PAMAM) induces quantitatively, and select the most effective kind of PAMAM with a certain terminal group for dentin remineralization, both for the first time. Prepared demineralized dentin specimens were divided into four groups: (1) dentin coated with deionized water, (2) dentin coated with PAMAM-OH, (3) dentin coated with PAMAM- $\mathrm{COOH}$, and (4) dentin coated with PAMAM- $\mathrm{NH}_{2}$. Specimens were then treated with artificial saliva at $37^{\circ} \mathrm{C}$ for 28 days. The remineralized dentin specimens were examined by transverse microradiography (TMR), hardness testing, scanning electron microscopy (SEM) and energy dispersive spectroscopy (EDS). The SEM images were also analyzed with Image-Pro Plus software. The three treatment groups all induced lower mineral loss, lower lesion depth, higher dentin hardness, higher blocking rate of dentin tubules and higher percentages of $\mathrm{Ca}$ and $\mathrm{P}$ elements than the control group. PAMAM- $\mathrm{NH}_{2}$ or PAMAM-COOH induced lower mineral loss, lower lesion depth and a higher blocking rate of dentin tubules than PAMAM-OH. There was no significant difference between PAMAM- $\mathrm{NH}_{2}$ and PAMAM-COOH with regard to mineral loss, lesion depth, dentin hardness, blocking rate of dentin tubules and percentages of $\mathrm{Ca}$ and $\mathrm{P}$ elements. In conclusion, PAMAM with different terminal groups could induce dentin remineralization, and PAMAM-NH 2 or PAMAM-COOH showed the strongest remineralization capabilities on demineralized dentin.
\end{abstract}

\section{Introduction}

Dentin, as one of the main components of teeth, is composed of hydroxyapatite (HA), organic matrix and water. Dentin is a biomineralized hard tissue of good strength and rigidity due to the hierarchical arrangement of HA., ${ }^{1,2}$ Demineralization and remineralization of dentin coexist all the time in the oral environment. $^{3}$ The disequilibrium between demineralization and remineralization could result in diseases like dental caries or dentin hypersensitivity. Dental caries is caused by bacterial metabolism. Bacteria colonize on tooth surfaces and biofilm is

\footnotetext{
${ }^{a}$ State Key Laboratory of Oral Diseases, National Clinical Research Center for Oral Diseases, Department of Cariology and Endodontics, West China Hospital of Stomatology, Sichuan University, No. 14, 3rd section, Renmin Road South, Chengdu 610041, Sichuan Province, China. E-mail: kunnengliang@163.com; jiyaoliscu@163. com; Tel: $+86-28-85501439$

${ }^{b}$ Department of Advanced Oral Sciences and Therapeutics, University of Maryland School of Dentistry, Baltimore, MD 21201, USA

${ }^{c}$ Center for Stem Cell Biology \& Regenerative Medicine, University of Maryland School of Medicine, Baltimore, MD 21201, USA

${ }^{d}$ Department of Mechanical Engineering, University of Maryland Baltimore County, Baltimore County, MD 21250, USA

${ }^{e}$ College of Polymer Science and Engineering, State Key Laboratory of Polymer Materials Engineering, Sichuan University, Chengdu 610065, China
}

formed. Bacteria metabolize carbohydrates derived from food and then produce acids, which breaks the acid-base equilibrium on the tooth surface. As a result, the physiological equilibrium between demineralization and remineralization breaks toward demineralization, dental caries consequently happens. Dentin can be exposed to oral environment in some clinical situations, such as, abrasion, erosion, or gingival recession. ${ }^{4}$ According to the hydrodynamic hypothesis, ${ }^{5}$ when dentin is demineralized by acids either from an acidic diet or from oral bacteria, the dentinal tubules will be exposed and the diameters of the dentinal tubules will be enlarged, which can result in dentin hypersensitivity. ${ }^{6-8}$ Remineralization of dentin can solve the disequilibrium between demineralization and remineralization, as well as can lead to dentinal tubule occlusion, which might help to solve the problems of dental caries and dentin hypersensitivity. Hence, remineralization of dentin is of high clinical significance and needs the development of innovative materials and methods. ${ }^{9}$ In addition, remineralization of demineralized dentin collagen fibrils is also crucial to improve dentin bonding stability, because dentin collagen fibrils are exposed by acid-etching or acidic resin monomers derived from self-etching primers or adhesives, and the degradation of resin infiltrated within collagen matrix caused by matrix metalloproteinases (MMP) at bonding interfaces may shorten 
bonding durability. ${ }^{10,11}$ However, remineralized dentin collagen fibrils are covered by mineral crystals, which can protect dentin collagen fibrils from the direct attack by MMP, thus can improve dentin bonding stability.

Demineralized dentin is mainly composed of collagen fibrils. Some studies believe that collagen fibrils, as the main composition of demineralized dentin, cannot initialize hydroxyapatite (HA) nucleation or growth, ${ }^{12-14}$ other studies argue that collagen fibrils are able to induce nucleation and apatite deposit by means of their carbonyl and carboxyl groups. ${ }^{15-17}$ Nevertheless, without the help of remineralization agents, the nucleation rate of collagen fibrils is too slow. ${ }^{18}$ Non-collagenous proteins (NCPs), which exist in the organic matrix of dentin, play an important role in dentin biomineralization. ${ }^{19-21}$ During biomineralization, NCPs act as nucleation templates within collagen fibrils, as well as control the growth of HA, which is the main component of dentin, ${ }^{22,23}$ but NCPs do not have abilities to induce remineralization in mature dentin. Therefore, excellent nucleation templates are needed in the remineralization of demineralized dentin, and efforts have been made to apply remineralization coatings onto tooth lesions in recent years. ${ }^{14,17,24-29}$

Poly(amido amine) (PAMAM) dendrimers have become a focus in the field of biomineralization, which are expected to duplicate the effects of NCPs and induce dentin remineralization. ${ }^{22,30}$ PAMAM dendrimers are synthesized by a divergent synthetic method beginning with an ethylene diamine core followed by amidoamine branching structure. They belong to a class of hyperbranched and hydrophilic polymers. PAMAM are highly-branched polymers characterized by the presence of internal cavities, a large number of reactive terminal groups with specific sizes and shapes. ${ }^{30}$ PAMAM dendrimers of different generations have different structures. The first and second generations are linear molecules, the third or higher generations are sphere molecules with more functional groups, which enable PAMAM molecules to absorb more calcium ions during remineralization. As the generation number increases, the number of functional groups doubles. The third generation of PAMAM have 32 terminal groups, and the fourth generation of PAMAM we used for our experiment have 64 terminal groups. PAMAM dendrimers have diversiform kinds of terminal groups, such as carboxyl-terminated PAMAM (PAMAM-COOH), hydroxyterminated PAMAM (PAMAM-OH), and amine-terminated PAMAM (PAMAM- $\mathrm{NH}_{2}$ ). PAMAM-COOH solution is acidic, PAMAM- $\mathrm{NH}_{2}$ solution is alkaline and PAMAM-OH solution is relatively neutral. Previous studies showed that they all have remineralization effectiveness on demineralized dentin. ${ }^{31-35}$ PAMAM- $\mathrm{NH}_{2}$ could regenerate minerals on the surfaces of both demineralized dentin and collagen fibrils, ${ }^{33,34}$ and could induce dentinal tubule occlusion. ${ }^{35}$ PAMAM-COOH showed the ability to induce intrafibrillar remineralization by absorbing calcium (Ca) and phosphate (P) ions within collagen fibrils. ${ }^{31}$ PAMAM$\mathrm{OH}$ also showed a moderate remineralization ability and had effects on dentinal tubule occlusion. ${ }^{32}$ However, most examinations used in these studies were qualitative examinations, which are subjective and relatively inaccurate. While the dentin remineralization ability of PAMAM is well-proven, the quantification of decrease in mineral loss or lesion depth when PAMAM is applied onto dentin demineralized lesion remains unstudied. Quantitative experiment is important and is still needed to demonstrate the remineralization degree accurately when PAMAM is coated onto the surface of demineralized dentin. In addition, there has been no report on comparing the remineralization effectiveness of PAMAM with different terminal groups on demineralized dentin. Therefore, it would be highly desirable to carry out a quantitative experiment demonstrating the remineralization degrees when different types of PAMAM are applied to demineralized dentin, which would in the meantime help to select the most effective type of PAMAM for dentin remineralization. It would provide significant evidence to make the right choice in future clinical application, such as the ingredient details and using methods of future commercial products.

Accordingly, the objectives of this study were: (1) to examine the remineralization degree quantitatively when PAMAM is coated onto demineralized dentin in simulated oral environment; (2) to compare the remineralization effectiveness of PAMAM-COOH, PAMAM-OH and PAMAM- $\mathrm{NH}_{2}$ on demineralized dentin, in order to select the most effective kind of PAMAM for dentin remineralization. It was hypothesized that: (1) PAMAM with three different terminal groups would all significantly remineralize the demineralized dentin in artificial saliva environment; (2) PAMAM with certain kind of terminal group could be selected as the most effective for dentin remineralization by quantitative comparison.

\section{Materials and methods}

\subsection{Sample preparation}

Extracted caries-free human third molars were collected at West China Hospital of Stomatology, Sichuan University, which had been approved by the Hospital's Institutional Review Board. Informed consent was obtained for experimentation with human subjects. The collected teeth were stored in $0.5 \%$ thymol at $4{ }^{\circ} \mathrm{C}$ after being cleaned. The storing period was no longer than four weeks before their use.

A thickness of $3.5 \pm 0.5 \mathrm{~mm}$ dentin disks were prepared by cutting each tooth at the cement-enamel junction using a lowspeed water cooled diamond saw (Minitom, Struers, Copenhagen, Denmark). The enamel on the surface of prepared disks was removed using 120-grit carbide polishing papers under running water. The samples were protected with acrylic resin. Then the coronal surfaces of the dentin disks were polished with 800, 1200 and 2400-grit carbide polishing papers under running water. The dentin disks were ultrasonicated using an ultrasonic cleaner (FS20, Fisher Scientific Co., Pittsburgh, PA, USA) in distilled water for $10 \mathrm{~min}$, in order to remove the smear layer caused by the polishing process. The hardness of all the prepared dentin samples was examined by a Vickers hardness tester (MMT-X7A, Matsuzawa, Japan) with a diamond indenter under a $25 \mathrm{gf}$ load for $10 \mathrm{~s}$. Five indentations were made in each sample, and only dentin samples whose Vickers hardness were between 0.6 and $0.8 \mathrm{GPa}$ were included in the following experiment. Each included dentin sample was demineralized with 
0.5 M ethylene diamine tetraacetic acid (EDTA) solution ( $\mathrm{pH}$ 8.0) at room temperature for $30 \mathrm{~min},{ }^{31,32}$ rinsed with deionized water for three times, and then cleaned ultrasonically for $10 \mathrm{~min}$. Half of the exposed window on each sample was sealed with two layers of acid-resistant nail varnish. The demineralized dentin samples were stored in calcium-free phosphate-buffered saline (PBS) at $4{ }^{\circ} \mathrm{C}$ before their use, which was prepared by dissolving $0.27 \mathrm{~g} \mathrm{~L}^{-1} \mathrm{KH}_{2} \mathrm{PO}_{4}, 1.42 \mathrm{~g} \mathrm{~L}^{-1} \mathrm{Na}_{2} \mathrm{HPO}_{4}, 8 \mathrm{~g} \mathrm{~L}{ }^{-1} \mathrm{NaCl}$ and $0.2 \mathrm{~g} \mathrm{~L}^{-1} \mathrm{KCl}$, adjusting $\mathrm{pH}$ to 7.4 with $\mathrm{HCl}$.

\subsection{Treatment of demineralized dentin disks}

The demineralized dentin disks were divided into four groups randomly. Each group was treated as described below.

(1) Control. Each demineralized dentin disk was coated with $100 \mu \mathrm{L}$ of distilled water which was kept on dentin for $1 \mathrm{~h}$. Then dentin disks were air dried to serve as negative control. ${ }^{34}$

(2) РАМАM-OH. Each demineralized dentin disk was coated with $100 \mu \mathrm{L}$ of the PAMAM-OH solution which was kept on dentin for $1 \mathrm{~h}$, and then the specimen was rinsed with distilled water to remove loose PAMAM-OH. ${ }^{34}$ The dentin disks were then air dried.

(3) PAMAM-СОOH. Each demineralized dentin disk was treated with PAMAM-COOH as described in (2).

(4) PAMAM-NH $\mathbf{N}_{2}$. Each demineralized dentin disk was treated with PAMAM- $\mathrm{NH}_{2}$ as described in (2).

These four groups are denoted control group, PAMAM-OH group, PAMAM-COOH group, and $\mathrm{PAMAM- \textrm {NH } _ { 2 }}$ group, respectively. Twelve specimen were tested for each group $(n=12)$. The present study used the 4th generation PAMAM-OH, PAMAM$\mathrm{COOH}$ and PAMAM- $\mathrm{NH}_{2}$, which were obtained commercially (Chenyuan Dendrimer Tech., Weihai, China). Each PAMAM solution above was prepared by dissolving $10 \mathrm{mg}$ PAMAM in $10 \mathrm{~mL}$ of distilled water to achieve a concentration of $1 \mathrm{mg}$ $\mathrm{mL}^{-1} \cdot{ }^{34}$ Both good remineralization effectiveness and biocompatibility were achieved at this concentration according to previous studies. ${ }^{32,34}$ The $100 \mu \mathrm{L}$ of PAMAM solution was used because it could cover the exposed dentin surface completely following previous studies. ${ }^{34,36} 1 \mathrm{~h}$ was used to ensure that PAMAM macromolecules could be immobilized on dentin via size-exclusion features of collagen fibrils and electrostatic interactions..$^{31,34}$

\subsection{Remineralization of demineralized dentin in artificial saliva}

All treated dentin samples were stored at $37^{\circ} \mathrm{C}$ in artificial saliva solution, which was prepared by dissolving $1.5 \mathrm{mmol} \mathrm{L}{ }^{-1} \mathrm{CaCl}_{2}$, $0.9 \mathrm{mmol} \mathrm{L}^{-1} \mathrm{KH}_{2} \mathrm{PO}_{4}, 130 \mathrm{mmol} \mathrm{L}{ }^{-1} \mathrm{KCl}, 1.0 \mathrm{mmol} \mathrm{L}^{-1} \mathrm{NaN}_{3}$ and $20 \quad \mathrm{mmol} \quad \mathrm{L}^{-1} \quad$ 4-(2-hydroxyethyl-)-1-piperazineethanesulfonic acid (HEPES), adjusting $\mathrm{pH}$ to 7.0 with $\mathrm{KOH}\left(1 \mathrm{mmol} \mathrm{L}{ }^{-1}\right) \cdot{ }^{37}$ Artificial saliva solution was replaced every $24 \mathrm{~h}$ with $6 \mathrm{~mL}$ of fresh solution.

\subsection{Transverse microradiography (TMR) examination}

Six dentin samples from different group were used for TMR examination. Sections about $300 \mu \mathrm{m}$ thick were cut vertically to the windows on the dentin surfaces using a diamond-coated band saw. All the sections were then polished to a thickness of approximately $100 \mu \mathrm{m}$, which was ensured by a digital micrometer (Mitu-toyo, Tokyo, Japan). Each slice was fixed on Plexiglass slides in a TMR sample holder (Inspektor Research Systems BV, Amsterdam, Netherlands). Slices were then microradiographed alongside an aluminum calibration step-wedge with a monochromatic CuK X-ray source (Philips, Eindhoven, Netherlands) operated at $20 \mathrm{kV}$ and $20 \mathrm{~mA}$ and an exposure time of $25 \mathrm{~s}$. Imaging software (Transversal Microradiography Software 2006, Inspektor Research Systems BV) was used to analyze the lesion depth, mineral loss and mineral content at selected depths. Eight slices were analyzed from each dentin disk. Ten TMR traces were measured on each slice: five traces within areas not exposed to artificial saliva solution and five within areas that had been exposed to artificial saliva solution.

Remineralization in the dentin lesion that occurred during artificial saliva treatment is calculated as: remineralization $R=$ $\left(M_{\text {before }}-M_{\text {after }}\right) / M_{\text {before }}$, where $M_{\text {before }}$ is mineral loss in dentin disk before remineralization, and $M_{\text {after }}$ is mineral loss in the same area of the lesion after remineralization..$^{38,39}$

\subsection{Hardness measurement}

At the 7th, 14th, 21st and 28th days, the samples of four groups were removed from artificial saliva for hardness measurement. The hardness of the sample surfaces was characterized using a Vickers hardness tester (MMT-X7A, Matsuzawa, Japan) with a diamond indenter under a 25 gf load for $10 \mathrm{~s}$. Five indentations were made in each sample and twelve dentin disks were tested for different groups. Vickers hardness of healthy dentin and dentin after demineralization without any treatment were also measured to serve as controls.

\subsection{Scanning electron microscopy (SEM) and energy dispersive spectroscopy (EDS) examination}

After 28 days, all dentin disks were removed out of the artificial saliva solution. Six samples for different groups were sputtercoated with gold and examined via SEM (Inspect F50; FEI, USA). EDS (INCA350, Oxford, UK) measurement was also applied, analyzing chemical compositions of the dentin. Levels of carbon (C), oxygen (O), P and Ca were measured every $5 \mu \mathrm{m}$ of the $300 \mu \mathrm{m}$ distance by EDS at a voltage of $15 \mathrm{kV}$. The scanned regions of interest (ROI) covered the whole dentin surface including tubules.

Five micrographs were obtained for each dentin sample at different areas. Images at a constant $10000 \times$ magnification, with a scale bar of $10 \mu \mathrm{m}$, obtained by SEM were then analyzed using ImagePro Plus v6.0 for Windows (SPSS Inc., Chicago, IL, USA). Tubules out of the image were not measured. Tubules overlapped the edges of marked area or confused data by appearing only in part were not measured. ${ }^{40}$ Blocking rate (BR), which means the ratio of the number of the occluded tubules to the number of all tubules in the image $(M)$, was included in the measurement. BR $=(1 \times N+0.5 \times n) / M .^{35} N$ is the number of tubules occluded by $>50 \%$ in the image, $n$ is the number of tubules occluded by $\leq 50 \%$ in the image, which were obtained using ImagePro Plus v6.0. The average of $\mathrm{BR}$ of five micrographs represented the $\mathrm{BR}$ value for 
a certain sample, and the average of BR of six samples represented the BR value for a certain group.

\subsection{Statistical analysis}

Statistical analyses were performed with SPSS software version 21.0 (SPSS, Inc., an IBM Company, Chicago, IL, USA). All data were checked for normal distribution with the KolmogorovSmirnov test. One-way analysis of variance (ANOVA) was performed to detect the significant effects of the variables. Student-Newman-Keuls multiple comparison tests were used at a $p$ value of 0.05 .

\section{Results}

\subsection{TMR examination}

Microradiographs showed dentin lesion after EDTA etched and remineralization. There was no noticeable remineralization in control group after 28 days. In contrast, dentin lesions in PAMAM-OH, PAMAM-COOH, and PAMAM- $\mathrm{NH}_{2}$ groups had significant remineralization (Fig. 1).

Fig. 2 shows the average mineral profiles of the dentin specimens under 4 treatments or without any treatment, and the values of mineral loss and lesion depth are shown in Table 1. No significant difference between specimens without treatment and specimens treated with distilled water was observed. PAMAM-COOH, PAMAM-NH $\mathrm{N}_{2}$ and PAMAM-OH groups resulted in significantly lower mineral loss and lesion depth than control group. PAMAM- $\mathrm{NH}_{2}$ and PAMAM-COOH induced lower mineral loss and lesion depth than PAMAM-OH. The remineralization values (Fig. 3) showed that dentin lesions with PAMAM- $\mathrm{NH}_{2}$ or PAMAM-COOH had the highest remineralization (mean $\pm \mathrm{SD}$ ) of $82.18 \pm 2.96 \%, 76.34 \pm 4.53 \%$, respectively, higher than the $56.30 \pm 8.31 \%$ for the PAMAM-OH group.

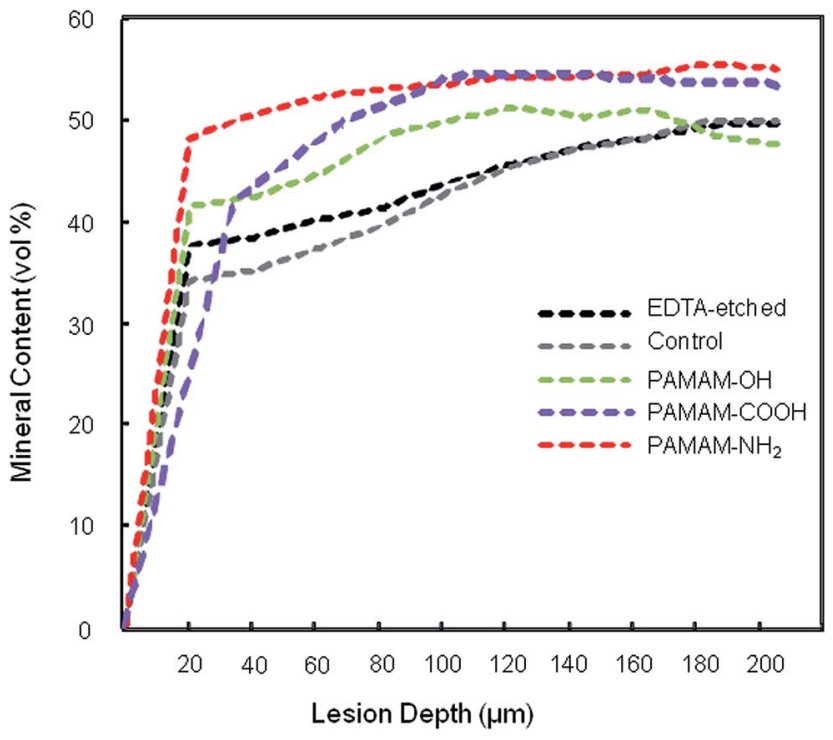

Fig. 2 Average mineral content profiles of various treatment groups or EDTA-etched without any treatment. Three kinds of PAMAM groups all resulted in higher mineral content than control group or EDTA-etched without treatment, of which PAMAM- $\mathrm{NH}_{2}$ and PAMAM-COOH groups had the highest mineral content.

\subsection{Hardness measurement}

The results of hardness measurement are shown in Fig. 4. The hardness of healthy dentin and EDTA-etched dentin were almost the same for the four groups. After artificial saliva immersion, the hardness of control group hardly changed. The dentin hardness of PAMAM-OH, PAMAM-COOH, PAMAM- $\mathrm{NH}_{2}$ groups increased to $0.59 \pm 0.03 \mathrm{GPa}, 0.62 \pm 0.05 \mathrm{GPa}, 0.65 \pm$ $0.02 \mathrm{GPa}$, respectively. Significant difference was observed

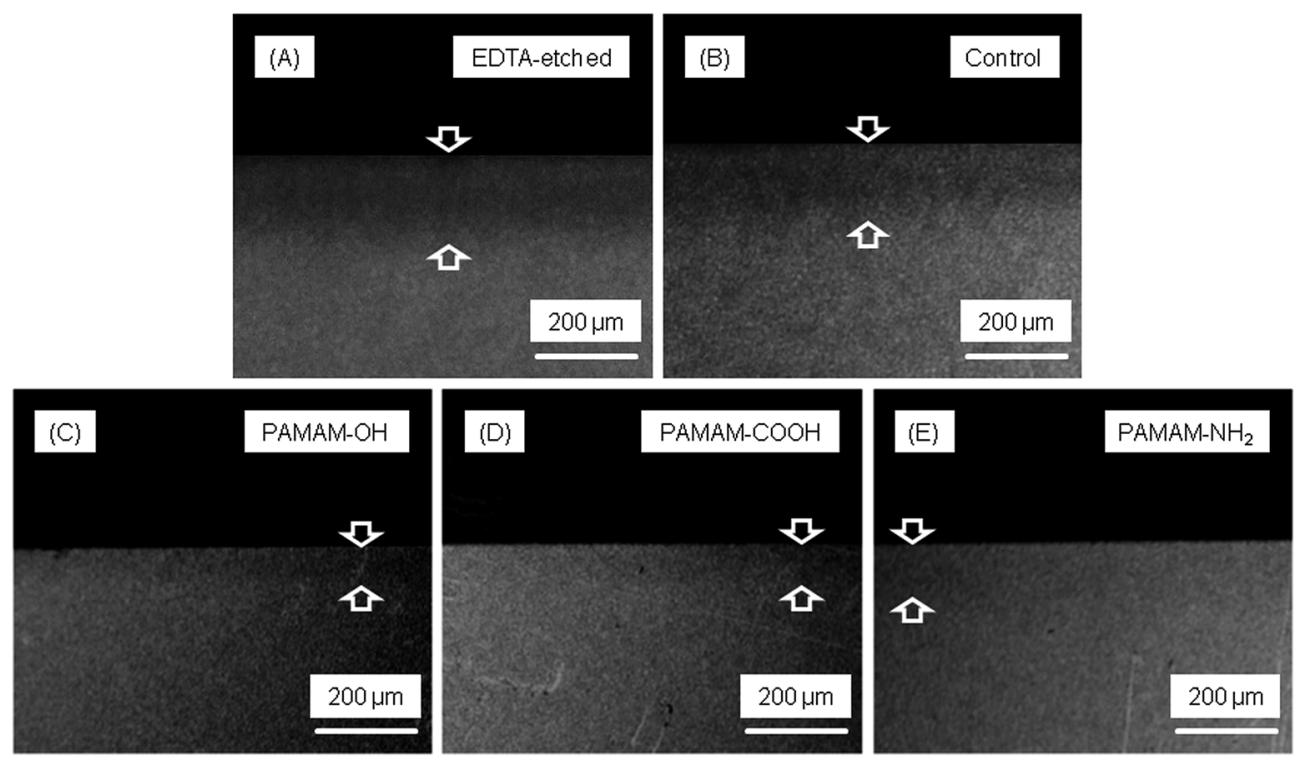

Fig. 1 Representative examples of microradiographs of dentin lesions (arrows). (A) There was significant dentin lesion after EDTA etched; (B) there was little remineralization in dentin in the control group; there was remineralization in dentin in the (C) PAMAM-OH group, (D) PAMAM$\mathrm{COOH}$ group, and (E) PAMAM- $\mathrm{NH}_{2}$ group, respectively. 
Table 1 Mineral loss and lesion depth values after different treatments $^{a}$

\begin{tabular}{lcc}
\hline Treatment & $\begin{array}{l}\text { Mineral loss } \\
(\text { vol\% } \mu \mathrm{m})\end{array}$ & $\begin{array}{l}\text { Lesion depth } \\
(\mu \mathrm{m})\end{array}$ \\
\hline $\begin{array}{l}\text { EDTA-etched without } \\
\text { treatment }\end{array}$ & $1945.63 \pm 630.81^{\mathrm{a}}$ & $131.73 \pm 7.05^{\mathrm{d}}$ \\
Deionized water & $1962.00 \pm 446.00^{\mathrm{a}}$ & $127.24 \pm 12.37^{\mathrm{d}}$ \\
PAMAM-OH & $733.64 \pm 102.11^{\mathrm{b}}$ & $68.67 \pm 8.62^{\mathrm{e}}$ \\
PAMAM-COOH & $446.11 \pm 128.98^{\mathrm{c}}$ & $42.09 \pm 5.24^{\mathrm{f}}$ \\
PAMAM-NH $_{2}$ & $254.80 \pm 70.30^{\mathrm{c}}$ & $37.75 \pm 5.99^{\mathrm{f}}$
\end{tabular}

${ }^{a}$ All values are presented as means $\pm \mathrm{SD}$. The different letters indicate statistically significant differences $(p<0.05)$.

between PAMAM-OH group and PAMAM- $\mathrm{NH}_{2}$ group, while no significant difference was detected either between PAMAM$\mathrm{COOH}$ group and PAMAM- $\mathrm{NH}_{2}$ group, or between PAMAM$\mathrm{COOH}$ group and PAMAM-OH group.

\subsection{SEM and EDS examination}

Fig. 5 shows SEM images of representative specimens from each group. Only a few small minerals deposited in the dentinal tubules for the control group, with dentinal tubules still completely open. PAMAM- $\mathrm{NH}_{2}$ and PAMAM-COOH elicited similar effect on tubule occlusion, both of which were more noticeable than PAMAM-OH group.

The BR of the dentin tubules for different groups are shown in Fig. 6(A). The BR of PAMAM-COOH and PAMAM- $\mathrm{NH}_{2}$ groups were significantly higher than PAMAM-OH group, and the BR of PAMAM-OH group was significantly higher than control group.

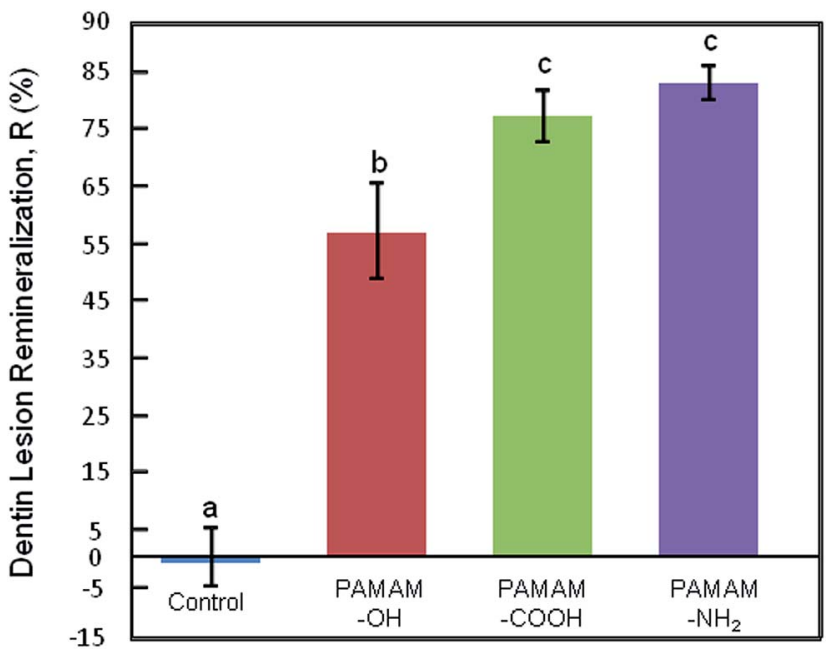

Fig. 3 Remineralization of human dentin lesions after 28 day artificial saliva solution immersion. Dissimilar letters indicate significantly different values $(P<0.05)$. Control group showed no remineralization, while three other groups showed excellent remineralization, of which PAMAM- $\mathrm{NH}_{2}$ and PAMAM-COOH groups showed the highest remineralization rate. Remineralization of dentin lesion in PAMAM- $\mathrm{NH}_{2}$, PAMAM-COOH and PAMAM-OH groups was $82.18 \pm 2.96 \%, 76.34 \pm$ $4.53 \%, 56.30 \pm 8.31 \%$, respectively (mean $\pm S D, n=6$ ).

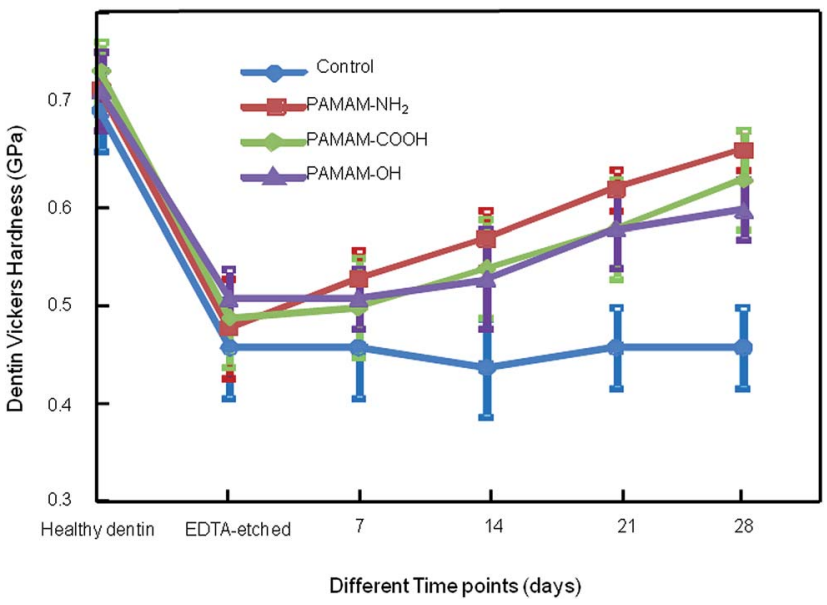

Fig. 4 Dentin hardness of four groups. The hardness of healthy dentin, after being acid-etched, and after 7, 14, 21, and 28 days of artificial saliva immersion for: control group, PAMAM-OH group, PAMAM$\mathrm{COOH}$ group, and PAMAM- $\mathrm{NH}_{2}$ group. Dentine hardness in three treatment groups increased steadily, however, dentin hardness of the control group did not change significantly compared with the hardness of dentin after being acid-etched during the whole remineralization period ( $p>0.05$ ) (mean $\pm \mathrm{SD}, n=12$ ).

The atomic percentages of $\mathrm{Ca}$ and $\mathrm{P}$ elements in the tested dentin surfaces are presented in Fig. 6(B and $\mathrm{C}$ ). The atomic percentages of $\mathrm{Ca}$ and $\mathrm{P}$ in PAMAM-OH, PAMAM-COOH, PAMAM- $\mathrm{NH}_{2}$ groups were significantly higher than the control group, which demonstrated that remineralization was induced in these treatment groups.

\section{Discussion}

The present study quantitatively tested dentin remineralization extent after coated with PAMAM and compared the effects of PAMAM with different terminal groups on dentin remineralization for the first time. Although three kinds of PAMAM all showed good abilities to induce dentin remineralization, PAMAM- $\mathrm{NH}_{2}$ or PAMAM-COOH achieved greater remineralization effectiveness of the demineralized dentin than PAMAM-OH in vitro.

Realizing dentin remineralization is of high clinical value when facing the problems of dental caries, dentin hypersensitivity, and short dentin bonding durability. Remineralization of dentin is more difficult to achieve than enamel, and remains a big challenge in clinical dentistry. ${ }^{\mathbf{4 1 4 2}}$ Different materials have been reported to have the ability to promote dentin remineralization. For example, nanoparticles of amorphous calcium phosphate (NACP) was added into composites to induce dentin remineralization, as NACP could release $\mathrm{Ca}$ and $\mathrm{P}$, as well as increase the $\mathrm{pH}$ of acidic environment. ${ }^{43}$ Polyacrylic acid (PAA) was also reported to induce dentin remineralization, as it could adsorb onto metastable amorphous calcium phosphate nanoprecursors, which was then stabilized as amorphous nanocrystals by PAA, these nanocrystals then transformed into larger apatite platelets. ${ }^{\mathbf{1 2}}$ Dentin is made up of inorganic mineral, extracellular matrix (ECM) and aqueous fluids. ${ }^{44}$ NCPs in ECM 

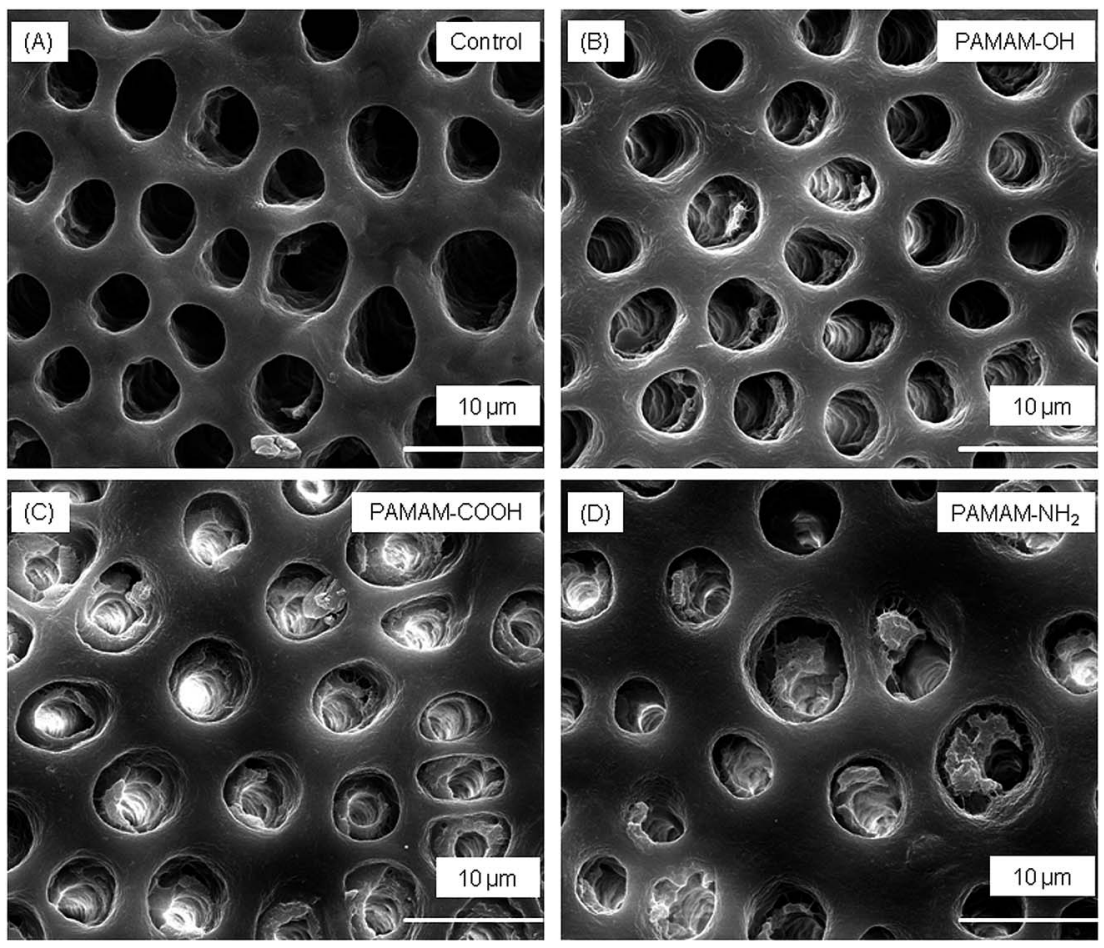

Fig. 5 SEM micrographs of demineralized dentin occlusal-section perpendicular to dentinal tubule axis after 28 day artificial saliva immersion: (A) control group, (B) PAMAM-OH group, (C) PAMAM- $\mathrm{COOH}$ group, and (D) PAMAM-NH 2 group. (A) Showed that few minerals regenerated, (B-D) showed that minerals precipitated in demineralized dentin surface. Among them, (B) showed a moderate dentin remineralization, (C, D) showed a stronger mineral regeneration.

are rich in acidic amino acids like aspartic acid and glutamic acid and can regulate biomineralization of dentin. ${ }^{45}$ However, NCPs cannot induce remineralization in mature dentin. Imitating the functions of NCPs and achieving biomimetic mineralization of dentin has become a goal of both dentistry and biomaterial fields. A nucleation template acts as the core of biomineralization process, ${ }^{14}$ as a result, demineralized dentin treated with a nucleation template can elicit remineralization effect. PAMAM dendrimer has been demonstrated as an excellent nucleation template. ${ }^{36,46}$ It is a class of mono-dispersed nanomaterials with many branches radiating from a central core and adsorb to the surface of hydroxyapatite through its calcium coordination sites. ${ }^{47}$ Its calcium coordination sites can also attract free calcium phosphate from saliva onto the crystal surface of demineralized dentin, which promotes HA crystal growth along its long axis. ${ }^{48,49}$ PAMAM with different ending functional groups have been demonstrated to be effective to induce dentin remineralization. ${ }^{31-35}$ PAMAM-based molecules were also synthesized to induce remineralization. For example, an amphiphilic PAMAM dendritic molecule mimicking the function of amelogenin was reported to fabricate oriented hydroxyapatite. ${ }^{50}$ However, examinations in these previous studies are almost qualitative, for example, SEM and transmission electron microscopy (TEM). There is still a lack of quantitative examinations to clarify the remineralization extent induced by PAMAM. It is also difficult to conclude which kind of PAMAM is the most effective on dentin remineralization according to previous studies. Our present study filled the two blanks of previous studies, thus provided accurate and reliable evidence for future clinical application details of PAMAM. We chose PAMAM-OH, PAMAM-COOH and PAMAM- $\mathrm{NH}_{2}$, which were most widely commercially available kinds of PAMAM, in our experiment. However, other kinds of PAMAM were also used to enhance dentin remineralization, such as phosphorylated PAMAM. ${ }^{51,52}$ Examinations in these papers were also mostly qualitative, such as SEM and TEM. Quantitative examinations like X-ray diffraction (XRD) analysis were also used, which were different from the examinations in our present study. Thus, it is difficult to compare our obtained results with other PAMAM formulation on dentin remineralization effectiveness now, further relevant studies are still needed in the future.

We used TMR examination to determine the remineralization extent when PAMAM is coated onto demineralized dentin because TMR is regarded as the standard method for the measurement of changes in mineral content of the dental hard tissues. ${ }^{53} \mathrm{~A}$ monochromatic X-ray beam is used in TMR examination to determine mass attenuation which is consequently converted to volume percent mineral (vol\% min). Surface hardness has been used for quantifying dental caries lesions in vitro extensively. ${ }^{36,54,55}$ It has been shown that indentation lengths could indirectly reflect the demineralization degree of dental hard tissue lesions. ${ }^{56}$ ImagePro Plus v6.0 was used to help calculate the BR values of SEM images, which quantified the abilities to induce dentin tubule occlusion. EDS was used to determine the atomic percentages of $\mathrm{Ca}$ and $\mathrm{P}$ elements in dentin surfaces after PAMAM is applied, which reflected remineralization indirectly. 

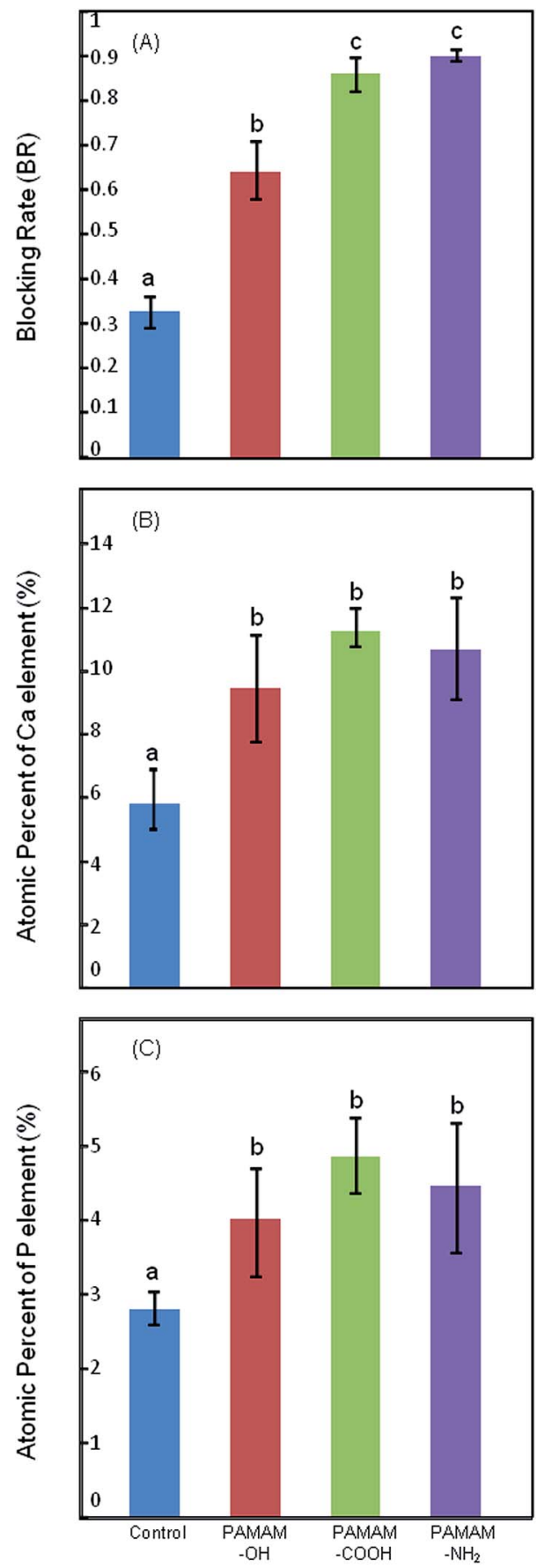

Fig. 6 Blocking rate, atomic percentages of $\mathrm{Ca} / \mathrm{P}$ element of human dentin lesions after 28 day artificial saliva solution immersion. Dissimilar letters indicate significantly different values $(P<0.05)$. The blocking rate of PAMAM- $\mathrm{NH}_{2}$ or PAMAM-COOH group was higher than PAMAM-OH group, which was higher than the control group. The atomic percentages of $\mathrm{Ca}$ and $\mathrm{P}$ in PAMAM-OH, PAMAM-COOH, $\mathrm{PAMAM}-\mathrm{NH}_{2}$ groups were higher than the control group (mean $\pm \mathrm{SD}$, $n=6)$.

TMR examination concluded that demineralized dentin treated with PAMAM- $\mathrm{NH}_{2}$ or PAMAM-COOH resulted in more reversion of lesion depth and mineral loss compared with PAMAM-OH. Dentin hardness measurement also showed that the increase of surface hardness in PAMAM- $\mathrm{NH}_{2}$ group was more significant than that in PAMAM-OH group. However, the dentin hardness after 28 days of PAMAM- $\mathrm{COOH}$ group demonstrated no significant difference between either PAMAM$\mathrm{OH}$ group or PAMAM- $\mathrm{NH}_{2}$ group. The results of hardness measurement were different from the results of TMR examination. It has been reported that although hardness gives important evidence regarding mechanical resilience of dental hard tissue, ${ }^{2,56}$ it cannot be used to judge mineral content reliably, particularly when it comes to dentin. Hardness is not an adequate alternative to TMR when estimating the mineral content of dentin. The relationship between hardness and TMR was weak and not linear. ${ }^{57}$ Cross-sectional hardness may reflect the mechanical resilience of dental hard tissue more accurately than surface hardness since the penetration depth of the diamond into dental lesion may be about $10 \mu \mathrm{m}$, which may not reflect deeper alterations. ${ }^{56}$ It has also been demonstrated that when examining dentin hardness, results obtained from the dehydrated organic dentin matrix might not reflect true mechanical behavior of remineralized dentin under the physiological condition, which is a hydrated condition. ${ }^{2}$ Thus, we can still conclude safely that PAMAM- $\mathrm{NH}_{2}$ or PAMAM-COOH on dentin remineralization is more effective than PAMAM-OH, according to the results of TMR.

PAMAM- $\mathrm{NH}_{2}$ or PAMAM-COOH showed a greater remineralization ability may be attributed to the reasons as follows. PAMAM macromolecules are thought to bind to demineralized collagen fibrils by both size-exclusion features and electrostatic interactions of the collagen. ${ }^{34}$ Size-exclusion is an important feature of collagen fibrils, which are the main parts of demineralized dentin. The size-exclusion feature means that collagen fibrils allow molecules smaller than $6 \mathrm{kDa}$ to pass through freely while prevent molecules larger than $40 \mathrm{kDa}$ from entering. ${ }^{58}$ Molecules with a molecular weight between 6 and $40 \mathrm{kDa}$ is able to retain within collagen fibrils, and the molecular weight of the 4th generation of PAMAM with three kinds of ending functional groups, which we used in this study, are all within this range. However, amino groups are positively charged and carboxyl groups are negatively charged in a neutral condition. Hydroxyl groups are relatively neutral, on the contrary. There are quantities of charged sites on collagen fibrils. ${ }^{59}$ Therefore, more charged groups in PAMAM- $\mathrm{NH}_{2}$ and PAMAM-COOH may help more molecules bind to the collagen fibrils than PAMAM-OH by electrostatic interactions. Immobilized PAMAM then acts as a nucleation template during the dentin remineralization process. In addition, PAMAM- $\mathrm{NH}_{2}$ and PAMAM-COOH's ability of attracting free calcium phosphate may be more excellent than PAMAM-OH, as it has been reported that the order of binding affinity of functional groups to calcium ion was carboxylate $>$ amino $>$ hydroxy group. ${ }^{60}$ Therefore, PAMAM$\mathrm{COOH}$ or PAMAM- $\mathrm{NH}_{2}$ could attract more calcium phosphate, resulting in more minerals and better remineralization effects.

In the SEM images, the few regenerated crystals in control group might be due to heterogeneous deposition of minerals through free calcium and phosphate ions from artificial saliva onto the residue apatite seed crystallites of demineralized dentin. In contrast, dentinal tubules in the other three groups were partially or fully occluded by dense crystals. We calculated 
the blocking rate (BR) by the number of closed tubules which was determined by ImagePro Plus v6.0, and the results were consistent to the results of TMR. According to EDS results, three kinds of PAMAM groups showed significantly higher content of Ca and $P$ values than the control group, indicating that PAMAM macromolecules absorbed more calcium and phosphorus from artificial saliva, which led to the subsequent mineral regeneration.

There are still some limitations in our study. Since only in vitro experiment was conducted in our study, future studies may consider remineralization conditions that more closely resemble the clinical situation. In addition, intrafibrillar remineralization is attracting more and more attention for the precise nanostructural architecture of mineralized dentin. ${ }^{\mathbf{1 2 , 6 1 - 6 4}}$ TEM observation could be employed to examine whether PAMAM dendrimer has the ability to induce intrafibrillar remineralization within dentin collagen fibrils in future studies, which will help to explain the mechanism more precisely. PAMAM- $\mathrm{NH}_{2}$ or PAMAM-COOH could potentially be applied to various dental applications including, for example, toothpaste or rinse solution, to promote the remineralization of demineralized dentin.

\section{Conclusions}

Within the limits of this study, it can be concluded that PAMAM- $\mathrm{NH}_{2}$ or PAMAM-COOH is more effective on the remineralization of demineralized dentin than PAMAM-OH, including decreasing mineral loss and lesion depth more significantly, and inducing more effective dentinal tubule occlusion. The remineralization rate of dentin lesions after treatment of PAMAM-NH $\mathrm{N}_{2}$, PAMAM-COOH and PAMAM-OH in artificial saliva was $82.18 \pm 2.96 \%, 76.34 \pm 4.53 \%, 56.30 \pm$ $8.31 \%$, respectively. PAMAM- $\mathrm{NH}_{2}$ or PAMAM-COOH may have great potential in clinic treatment in the future.

\section{Conflicts of interest}

There are no conflicts to declare.

\section{Acknowledgements}

This work was supported by National Natural Science Foundation of China (81670977, 81170958, J. Li and 81400508, L. He), and Sichuan Province Science and Technology support program (2017SZ0030).

\section{References}

1 S. J. Omelon and M. D. Grynpas, Chem. Rev., 2008, 108, 46944715.

2 L. E. Bertassoni, S. Habelitz, J. H. Kinney, S. J. Marshall and G. W. Marshall, Caries Res., 2009, 43, 70-77.

3 D. J. White, Adv. Dent. Res., 1995, 9, 175-193.

4 Z. Wang, T. Jiang, S. Sauro and Y. Wang, J. Dent., 2011, 39, 746-756.
5 M. Brannstrom, L. A. Linden and G. Johnson, J. Dent. Res., 1968, 47, 679-682.

6 E. G. Absi, M. Addy and D. Adams, J. Clin. Periodontol., 1987, 14, 280-284.

7 M. Yoshiyama, J. Masada, A. Uchida and H. Ishida, J. Dent. Res., 1989, 68, 1498-1502.

8 M. Yoshiyama, Y. Noiri, K. Ozaki, A. Uchida, Y. Ishikawa and H. Ishida, J. Dent. Res., 1990, 69, 1293-1297.

9 J. D. Featherstone, Remineralization, the natural caries repair process - the need for new approaches, Adv. Dent. Res., 2009, 21, 4-7.

10 Y. K. Kim, S. Mai, A. Mazzoni, Y. Liu, A. Tezvergil-Mutluay and K. Takahashi, Acta Biomater., 2010, 6, 3729-3739.

11 Y. Liu, L. Tjaderhane, L. Breschi, A. Mazzoni, N. Li and J. Mao, J. Dent. Res., 2011, 90, 953-968.

12 F. R. Tay and D. H. Pashley, Biomaterials, 2008, 29, 11271137.

13 Y. Fan, Z. Sun and J. Moradian-Oldak, Biomaterials, 2009, 30, 478-483.

14 Y. Z. Zhou, Y. Cao, W. Liu, C. H. Chu and Q. L. Li, ACS Appl. Mater. Interfaces, 2012, 4, 6901-6910.

15 W. Zhang, S. S. Liao and F. Z. Cui, Chem. Mater., 2003, 15, 3221-3226.

16 W. J. Landis, F. H. Silver and J. W. Freeman, J. Mater. Chem., 2006, 16, 1495-1503.

17 Q. Wang, X. M. Wang, L. L. Tian, Z. J. Cheng and F. Z. Cui, Soft Matter, 2011, 7, 9673-9680.

18 T. Saito, A. L. Arsenault, M. Yamauchi, Y. Kuboki and M. A. Crenshaw, Bone, 1997, 21, 305-311.

19 S. Gajjeraman, K. Narayanan, J. Hao, C. Qin and A. George, J. Biol. Chem., 2007, 282, 1193-1204.

20 S. Weiner, Biomineralization: a structural perspective, $J$. Struct. Biol., 2008, 163, 229-234.

21 L. E. Bertassoni, Dent. Mater., 2017, 33, 637-649.

22 J. J. J. M. Donners, R. J. M. Nolte and N. A. J. M. Sommerdijk, Adv. Mater., 2003, 15, 313-316.

23 A. George and A. Veis, Chem. Rev., 2008, 108, 4670-4693.

24 A. V. Kaneshiro, S. Imazato, S. Ebisu, S. Tanaka, Y. Tanaka and H. Sano, Dent. Mater., 2008, 24, 1420-1427.

25 J. Kim, D. D. Arola, L. Gu, Y. K. Kim, S. Mai and Y. Liu, Acta Biomater., 2010, 6, 2740-2750.

26 Q. L. Li, T. Y. Ning, Y. Cao, W. B. Zhang, M. L. Mei and C. H. Chu, BMC Biotechnol., 2014, 14, 32.

27 Q. Ruan and J. Moradian-Oldak, J. Mater. Chem. B, 2015, 3, 3112-3129.

28 H. Miyajima, T. Ishimoto, S. Ma, J. Chen, T. Nakano and S. Imazato, Dent. Mater. J., 2016, 35, 399-407.

29 S. Prajapati, Q. Ruan, K. Mukherjee, S. Nutt and J. MoradianOldak, J. Dent. Res., 2017, DOI: 10.1177/0022034517728504.

30 S. Svenson and D. A. Tomalia, Adv. Drug Delivery Rev., 2005, 57, 2106-2129.

31 J. H. Li, J. J. Yang and J. S. Li, Biomaterials, 2013, 34, 67386747.

32 K. N. Liang, Y. Gao and J. Y. Li, RSC Adv., 2014, 4, 4349643503.

33 K. N. Liang, Y. Gao and J. Y. Li, J. Biomater. Sci., Polym. Ed., 2015, 26, 963-974. 
34 K. N. Liang, H. Yuan and J. Y. Li, Macromol. Mater. Eng., 2015, 300, 107-117.

35 Y. Gao, K. N. Liang and J. Y. Li, Materials, 2017, 10, 384.

36 K. N. Liang, M. D. Weir, X. Xie, L. Wang, M. A. Reynolds and J. Li, Dent. Mater., 2016, 32, 1429-1440.

37 J. M. ten Cate and P. P. Duijsters, Caries Res., 1982, 16, 201210.

38 S. E. Langhorst, J. N. O'Donnell and D. Skrtic, Dent. Mater., 2009, 25, 884-891.

39 M. D. Weir, L. C. Chow and H. H. Xu, J. Dent. Res., 2012, 91, 979-984.

40 T. R. Ahmed, N. J. Mordan, M. S. Gilthorpe and D. G. Gillam, J. Oral Rehabil., 2005, 32, 589-597.

41 J. M. ten Cate, J. J. Damen and M. J. Buijs, Caries Res., 1998, 32, 141-147.

42 Y. K. Kim, C. K. Yiu, J. R. Kim, L. Gu, S. K. Kim and R. N. Weller, J. Dent. Res., 2010, 89, 230-235.

43 H. H. K. Xu, J. L. Moreau, L. Sun and L. C. Chow, Dent. Mater., 2011, 27, 762-769.

44 R. Wang and S. Weiner, Connect. Tissue Res., 1998, 39, 269279.

45 G. He, A. Ramachandran, T. Dahl, S. George, D. Schultz and D. Cookson, J. Biol. Chem., 2005, 280, 33109-33114.

46 A. Lungu, E. Rusen, L. M. Butac and I. C. Stancu, Dig. J. Nanomater. Biostruct., 2009, 4, 97-107.

47 D. Wu, J. Yang, J. Li, L. Chen, B. Tang and X. Chen, Biomaterials, 2013, 34, 5036-5047.

48 H. Chen, M. Banaszak Holl, B. G. Orr, I. Majoros and B. H. Clarkson, J. Dent. Res., 2003, 82, 443-448.

49 S. J. Yan, Z. H. Zhou, F. Zhang, S. P. Yang, L. Z. Yang and X. B. Yu, Mater. Chem. Phys., 2006, 99, 164-169.
50 S. Yang, H. He, L. Wang, X. R. Jia and H. L. Feng, Chem. Commun., 2011, 47, 10100-10102.

51 T. D. Wang, S. Yang, L. Wang and H. L. Feng, RSC Adv., 2015, 5, 11136.

52 H. Zhang, J. J. Yang, L. B. He and J. S. Li, Colloids Surf., B, 2015, 128, 304-314.

53 J. J. Ten Bosch and B. Angmar-Mansson, J. Dent. Res., 1991, 70, 2-14.

54 D. J. White, Caries Res., 1988, 22, 27-36.

55 A. C. Magalhaes, L. P. Comar, D. Rios, A. C. Delbem and M. A. Buzalaf, J. Dent., 2008, 36, 158-162.

56 A. C. Magalhaes, B. M. Moron, L. P. Comar, A. Wiegand, W. Buchalla and M. A. Buzalaf, Caries Res., 2009, 43, 474483.

57 B. M. Moron, L. P. Comar, A. Wiegand, W. Buchalla, H. Yu and M. A. Buzalaf, Caries Res., 2013, 47, 162-170.

58 D. Toroian, J. E. Lim and P. A. Price, J. Biol. Chem., 2007, 282, 22437-22447.

59 L. S. Gu, Y. K. Kim, Y. Liu, K. Takahashi, S. Arun and C. E. Wimmer, Acta Biomater., 2011, 7, 268-277.

60 X. Wang, J. Ma, Y. Wang and B. He, Biomaterials, 2001, 22, 2247-2255.

61 L. Gu, Y. K. Kim, Y. Liu, H. Ryou, C. E. Wimmer and L. Dai, J. Dent. Res., 2011, 90, 82-87.

62 X. T. Wu, M. L. Mei, Q. L. Li, C. Y. Cao, J. L. Chen and R. Xia, Materials, 2015, 8, 7889-7899.

63 L. S. Gu, X. Q. Huang, B. Griffin, B. R. Bergeron, D. H. Pashley and L. N. Niu, Acta Biomater., 2017, 61, 144-156.

64 L. N. Niu, S. E. Jee, K. Jiao, L. Tonggu, M. Li and L. Wang, Nat. Mater., 2017, 16, 370-378. 